\title{
Enfermedad inflamatoria intestinal: parcelas etiopatogénicas a hilvanar
}

Sánchez-Fayos Calabuig P, Martín Relloso MJ, González Guirado A, Porres Cubero JC. Enfermedad inflamatoria intestinal: parcelas etiopatogénicas a hilvanar. An Med Interna (Madrid) 2004; 21: 105-107.

Con el término impreciso de enfermedad inflamatoria intestinal (EII) se engloba a dos entidades anatomoclínicas clásicamente diferenciadas -la colitis ulcerosa (CU) y la Enfermedad de Crohn (EC)- cuyo común denominador es la inflamación crónica y recurrente de la pared del tubo digestivo, sin causa claramente definida.

Pocos argumentos, dentro de la moderna gastroenterología, superan en complejidad al "cómo" y el "porqué" de la EII. Y a pesar de un considerable esfuerzo multidisciplinario, sólo se ha logrado intuir algunas circunstancias etiológicas y sospechar ciertos caminos patogénicos, cuyo acoplamiento recíproco es, hoy por hoy, misión imposible (1-3).

A pesar de ello, si tuviésemos que resumir el significado biológico de la EII, a la vista de los conocimientos actuales, podríamos decir que parece ser la consecuencia de un conflicto entre antígenos (Ags) intraluminales (preferentemente microbianos) y el sistema celular inmunocompetente local. Todo ello bajo el impacto de una predisposición hereditaria no mendeliana de carácter poligénico y la modulación de ciertos factores ambientales (tabaquismo, anovulatorios orales, etc.). Sin embargo, entre los epítopos responsables de aquel conflicto no se puede descartar el papel de algunos autoantígenos mucosos (4).

Vamos a intentar hilvanar, en este trabajo, los retales etiopatogénicos mejor conocidos, a lo largo de diez puntos artificialmente ordenados, a sabiendas que la realidad debe ser otra; concretamente, la de un entramado complejo y denso de acontecimientos celulares y moleculares, enredados entre sí y algo diferentes en ambos fenotipos de EII.

1. En algún momento de la historia de la EII, se pensó en la posibilidad de que el conflicto inmunológico fuese desencadenado por Ags. alimentarios (fundamentalmente proteínas de la leche), aunque pronto se descartó esta sospecha. Lo más verosímil es que las proteínas antigénicas procedan de agentes microbianos que actúan desde la luz intestinal o desde la colonización de la pared del tubo digestivo $(2,3)$.

Aunque disponemos de datos sugerentes sobre el posible papel etiológico del Mycobacterium paratuberculosis (responsable de la enfermedad de Johne en los rumiantes) y no se puede descartar rotundamente que exista un germen causal todavía no descubierto, todo hace pensar que los Ags. responsables de aquel conflicto procedan de la microflora residente normal. Así lo apoyan el hallazgo, en estos pacientes, de títulos elevados de anticuerpos (Acs) séricos frente a bacterias indígenas y el desarrollo de la inflamación intestinal en los modelos experimentales en roedores $(5,6)$.

2. En algunos trabajos de investigación clínica, se ha observado un aumento de la permeabilidad del epitelio intestinal en la EC y en familiares de primer grado (aparentemente sanos) de pacientes con esta enfermedad $(4,7)$. Sea cual sea la etiología de este hallazgo, lo que es evidente es que facilita la absorción de Ags. intraluminales (bacterianos o no), lo que puede: provocar, amplificar y/o cronificar el proceso inflamatorio.

Esta disfunción epitelial puede ser secundaria a la propia inflamación de la EC ya declarada o incluso a las lesiones microscópicas subclínicas de familiares asintomáticos. Sin embargo, lo que todavía no está claro es si este evento podría ser un camino patogénico primario en la realización de EC, como parece serlo en ciertos modelos experimentales, en los que se ha manipulado los genes que codifican la síntesis de proteínas necesarias para la integridad del epitelio intestinal. (6).

El revés de esta moneda etiológica podría ser el papel protector que parece tener la nicotina del tabaco sobre el desarrollo de la CU, al restaurar los niveles normales de moco protector del epitelio colónico $(1,2)$.

3. La segunda línea defensiva frente a los microorganismos del tubo digestivo la forman los elementos celulares del llamado sistema inmune innato, es decir: macrófagos (MFGs) células dendríticas y lifoncitos NK ("natural killer"). En estos últimos años, se ha descubierto en monocitos y MFGs los receptores membranarios "Toll-like" y los receptores citosólicos Nod, especializados ambos en la captación de determinados patrones moleculares microbianos, tales como: lipopolisacáridos (LPS), lipoproteínas, peptidoglicanos, etc (8).

Hoy se sabe que existe al menos dos receptores específicos de los LPS de las bacterias gram-negativas, a saber: el receptor "Toll-like-4" y una proteína citosólica codificada por el gen Nod-2. El contacto entre aquella estructura molecular 